\title{
315 APPLICATION OF THE SITC IMMUNOTHERAPY RESISTANCE TASKFORCE DEFINITIONS OF ANTI-PD-1 RESISTANCE TO STUDIES EVALUATING PATIENTS WITH ADVANCED MELANOMA
}

${ }^{1}$ Irene Shui*, ${ }^{1}$ Emilie Scherrer, ${ }^{2}$ Andrew Frederickson, ${ }^{3}$ Eric Druyts, ${ }^{4}$ Hussein Tawbi. ${ }^{1}$ Merck and Co., Inc., Kenilworth, NJ, USA; ${ }^{2}$ PRECISIONheor, New York, NY, USA; ${ }^{3}$ Pharmalytics Group, Vancouver, Canada; ${ }^{4}$ MD Anderson Cancer Center, Houston, TX, USA

Background Until the recent 2020 publication by the Society for Immunotherapy of Cancer (SITC) Immunotherapy Resistance Taskforce, there was little consensus on defining primary and secondary resistance to anti-programmed cell death protein 1 monotherapy. Our objective was to characterize the clinical outcomes reported in peer-reviewed literature when categorized according to the SITC definitions.

Methods A systematic literature review (SLR) was conducted in Medical Literature Analysis and Retrieval System Online, Excerpta Medica database, and Cochrane Central Register of Controlled Trials (September 2015 - September 2020). Data were extracted on the proportion of patients with progressive disease (PD), and SITC criteria were applied to define resistance (table 1).

Results Thirty six studies were included, yielding 55 patient cohorts with data on PD; 42 cohorts reported PD specifically by best overall response, while 13 cohorts provided another definition of response. Response evaluation criteria in solid tumors (RECIST) 1.1 was most commonly used (37 cohorts), followed by immune-RECIST (7 cohorts). Twenty four cohorts reporting PD also had data on length of drug exposure, 13 on duration of response, 22 on utilization of a confirmatory scan, and 1 on whether progression occurred within 12 weeks of the last dose of therapy; no studies reported on all 4 criteria. We were able to partially apply SITC criteria for primary resistance to 42 of 55 cohorts and the proportion of patients with primary resistance ranged from $25 \%$ to $81 \%$. Only a few studies had data on secondary resistance, but none provided enough granularity to fully categorize secondary resistance by SITC.

Abstract 315 Table 1 SITC definitions of primary and secondary resistance in advanced disease

\begin{tabular}{|c|c|c|c|c|}
\hline $\begin{array}{l}\text { Resistance } \\
\text { Type }\end{array}$ & $\begin{array}{l}\text { Drug } \\
\text { exposure }\end{array}$ & Best response $^{*}$ & \begin{tabular}{|l|} 
Confirmatory \\
scan**
\end{tabular} & $\begin{array}{l}\text { Progressed on treatment } \\
\text { or } \leq 12 \text { weeks of last dose }\end{array}$ \\
\hline Primary & $\geq 6$ weeks & $\mathrm{PD} ; \mathrm{SD}$ for $<6 \mathrm{~m}^{* * *}$ & $\mathrm{Y}$ & Yes \\
\hline Secondary & $\geq 6$ months & $\mathrm{CR}, \mathrm{PR}, \mathrm{SD}$ for $>6 \mathrm{~m}$ & $\mathrm{Y}$ & Yes \\
\hline
\end{tabular}

Conclusions The majority of studies in this SLR did not report complete criteria to apply the SITC definitions; however, partial categorization of primary resistance was possible. The patient characteristics and outcomes reported varied, thus the data assessed were heterogeneous. Future studies should consider utilizing the SITC consensus definitions to harmonize how resistance is classified and facilitate meaningful context for clinical activity.

http://dx.doi.org/10.1136/jitc-2021-SITC2021.315 